\title{
PCSK9 inhibitors: The breakthrough lipid-lowering treatment at real-life setting A 2-year regional lipid clinic experience
}

\author{
Georgia Anastasiou, George Liamis, Haralampos Milionis, Moses Elisaf, \\ Eliza Christopoulou, Theodora Dimitriou, Evangelos N. Liberopoulos
}

Department of Internal Medicine, Faculty of Medicine, University of loannina, loannina, Greece

\begin{abstract}
Aim: Proprotein convertase subtilisin/kexin type 9 (PCSK9) inhibitors have been demonstrated to be safe and effective in low-density lipoprotein cholesterol (LDL-C) lowering and cardiovascular risk reduction. Data on clinical implementation of PCSK9 inhibitors in real life setting in Greece is limited. Thus, we report 2-year experience with PCSK9 inhibitors in clinical practice at a University Hospital Lipid Clinic. Patients and methods: This is a retrospective study of patients who were first prescribed a PCSK9 inhibitor during 2016-2018. Patients had either established cardiovascular disease (CVD) and/or familial hypercholesterolemia (FH) and LDL-C level $>100 \mathrm{mg} / \mathrm{dL}$ despite maximum tolerated high-intensity statin plus ezetimibe. Patient demographics, medical history, concomitant medications and laboratory results were documented during visits. Results: We included 37 patients (mean age 52 years, 56.8\% males). Of patients, 28 (76\%) had established CVD and 27 patients (74\%) had FH. Concerning treatment, 33 patients (89\%) were receiving high-intensity statin, while 35 patients (95\%) were also on ezetimibe $10 \mathrm{mg}$. Addition of PCSK9 inhibitors (51\% on evolocumab $140 \mathrm{mg}$ per 2 weeks (Q2W), 22\% on alirocumab $75 \mathrm{mg}$ Q2W and 27\% on alirocumab $150 \mathrm{mg}$ Q2W) resulted in a reduction of total cholesterol by $42 \%$ and LDL-C by $59 \%$ after 2 months $(p<0.05)$. These reductions remained unchanged after 1 and 2 years on treatment. Thirty patients (81\%) achieved LDL-C treatment goal following PCSK9i treatment. Four patients (11\%) developed minor adverse effects. No treatment discontinuation was reported. Conclusion: In real-life setting addition of PCSK9 inhibitors to maximally tolerated lipid-lowering therapy resulted in reductions of LDL-C levels of the magnitude seen in clinical studies. These reductions were sustainable during a 2-year follow-up.
\end{abstract}

KEY WORDS: PCSK9 inhibitors, dyslipidemia, familial hypercholesterolemia, statins, cardiovascular disease, ezetimibe

\section{Corresponding author:}

Dr Evangelos N. Liberopoulos, MD

Associate Professor of Medicine, Department of Internal Medicine, Faculty of Medicine, University of loannina 45110 loannina, Greece

Tel.: +302651007502, Fax: +302651007016

E-mail: elibero@uoi.gr

\section{INTRODUCTION}

Hypercholesterolemia is a well-established risk factor for atherosclerotic cardiovascular disease (ASCVD) and cardiovascular risk reduction is proportional to low-density 
lipoprotein cholesterol (LDL-C) lowering ${ }^{1,2}$. European Society of Cardiology/European Atherosclerosis Society (ESC/ EAS) and American College of Cardiology/American Heart Society (ACC/AHA) guidelines impose statin therapy as first line treatment for reducing LDL-C levels and associated cardiovascular risk $^{1,2}$. Ezetimibe addition to maximum tolerated statin is suggested for further LDL-C lowering ${ }^{1,2}$. However, a large proportion of patients do not achieve LDL$C$ goals under maximally tolerated lipid-lowering therapy or are statin intolerant ${ }^{3}$. This is also the case in Greece ${ }^{4,5}$.

Monoclonal antibodies inhibiting proprotein convertase subtilisin/kexin type 9 (PCSK9) have been shown to effectively lower LDL-C levels and associated cardiovascular risk ${ }^{6,7}$. Two fully human PCSK9 inhibitors (PCSK9i) are available, alirocumab and evolocumab, administered by subcutaneous injection at 75/150 mg every two weeks and $140 \mathrm{mg}$ every 2 weeks/420 mg once a month, respectively. In clinical studies PCSK9i lower LDL-C levels by $50-60 \%$ on top of maximally tolerated hypolipidemic treatment ${ }^{8-14}$. In addition, 3 randomized trials, FOURIER, ODYSSEY OUTCOMES and GLACOV, demonstrated that PCSK9i are associated with significant reductions of major cardiovascular events and atherosclerosis progression with an excellent safety profile $e^{6,7,15}$. Long-term studies have confirmed sustainability of LDL-C lowering up to 4 years $^{16-18}$.

In Greece PCSK9i are available since 2016 and are reimbursed in patients with either established ASCVD or familiar hypercholesterolemia (FH) and LDL-C level $>100$ $\mathrm{mg} / \mathrm{dL}$ despite maximum tolerated high-intensity statin plus ezetimibe ${ }^{19}$. However, data on the use of PCSK9i in real-life in Greece is limited. We report herein clinical experience with PCSK9i from an outpatient University hospital lipid clinic over 2 year follow-up.

\section{PATIENTS AND METHODS}

\section{Study population}

In the present study, we included consecutive patients attending the lipid clinic at the University Hospital of loannina, loannina, Greece from 2016 to 2018 who were prescribed a PCSK9i. Reimbursement of PCSK9i treatment was granted to patients with either established ASCVD or $\mathrm{FH}$ and LDL-C level $\geq 100 \mathrm{mg} / \mathrm{dL}$ while on maximum tolerated lipid-lowering therapy (rosuvastatin target dose 20-40 mg or atorvastatin target dose $40-80 \mathrm{mg}$ plus ezetimibe) and healthy lifestyle.

All patients prescribed PCSK9i were provided proper subcutaneous injection training. Patient characteristics, family history and concomitant medications were reported, and clinical examination and laboratory tests were performed at baseline visit, as well as after 2 months, 1 year and 2 years following PCSK9i administration. In addition, adverse events and compliance to PCSK9i therapy was reported during follow-up.

\section{Data analysis}

Analyses were performed descriptively via the Statistical Package for Social Sciences (SPSS) 21.0 software (SPSS, IBM corp). Continuous numeric variables are expressed as mean \pm standard deviation and median (interquartile: IQR) if Gaussian or non-Gaussian distributed, respectively. Categorical data are presented as total number and percentage. An ANOVA with repeated measures was used to compare group means where the participants are the same in each group. Chi square test was used to compare categorical data among the alirocumab and evolocumab treated group. Two-tailed significance was defined as $\mathrm{p}<0.05$.

\section{Ethics}

All participants gave written informed consent and the study protocol was approved by our institutional ethics committee. The research was performed according to the principles of the Declaration of Helsinki (1975).

\section{RESULTS}

\section{Baseline patient characteristics (Table 1)}

We included 37 patients [56.8\% men, age 54 years (IQR: 50-71)]. Of those, 28 (76\%) had established CVD [22 (60\%) coronary artery disease and $6(16 \%)$ a history of cerebrovascular event], 24 (65\%) had HeFH and 3 (8\%) had lower extremities arterial disease (LEAD)].

Nineteen individuals initiated evolocumab $140 \mathrm{mg}$ (Q2W) and 18 received alirocumab [8 alirocumab $75 \mathrm{mg}$ (Q2W) and 10 alirocumab $150 \mathrm{mg}$ (Q2W)]. Of the alirocumab treated group, 6 patients maintained the dose of $75 \mathrm{mg}$ (Q2W), while 2 patients were uptitrated to $150 \mathrm{mg}$ (Q2W) after the 2-month follow-up. No significant difference in baseline characteristics was noticed between the 2 groups. Eight patients ( 5 patients intolerant to statins, 1 with homozygous $\mathrm{FH}$ and 2 with heterozygous $\mathrm{FH}$ ) qualified PCSK9i treatment for primary prevention, while 29 patients for secondary prevention. Prior to initiation of PCSK9i, the vast majority of patients (90\%) were on dual maximally tolerated LLT (79\% on rosuvastatin $20-40 \mathrm{mg}$ and $11 \%$ on atorvastatin $40-80 \mathrm{mg}$ plus ezetimibe), $1 \mathrm{pa}-$ tient was on pitavastatin plus ezetimibe, 1 on pitavastatin monotherapy, 1 on ezetimibe monotherapy and 1 on colesevelam monotherapy (totally intolerable). No significant difference was observed in baseline characteristics among evolocumab and alirocumab treated groups $(p=N S)$. 
TABLE 1. Baseline patient characteristics

\begin{tabular}{|c|c|c|c|}
\hline & $\begin{array}{c}\text { All } \\
\text { patients }\end{array}$ & Evolocumab & Alirocumab \\
\hline Number & 37 & 19 & 18 \\
\hline \multirow[t]{2}{*}{ Age, years } & $54(50-71)$ & $52(49-65)$ & $55(50-76)$ \\
\hline & n (\%) & n (\%) & n (\%) \\
\hline Female & $16(43)$ & $10(53)$ & $6(33)$ \\
\hline Current smoking & $6(16)$ & $3(18)$ & $3(15)$ \\
\hline Coronary artery disease & $22(60)$ & $9(47)$ & $13(72)$ \\
\hline Cerebrovascular disease & $6(16)$ & $2(11)$ & $4(22)$ \\
\hline Hypertension & $17(46)$ & $7(37)$ & $10(56)$ \\
\hline Diabetes & $10(27)$ & $4(21)$ & $6(33)$ \\
\hline Carotid artery disease & $9(24)$ & $6(32)$ & $3(17)$ \\
\hline Chronic kidney disease & $4(11)$ & $1(5)$ & $3(17)$ \\
\hline \multicolumn{4}{|l|}{$\mathrm{FH}$} \\
\hline $\mathrm{HoFH}$ & $3(8)$ & $2(11)$ & $1(6)$ \\
\hline $\mathrm{HeFH}$ & $24(65)$ & $8(42)$ & $16(89)$ \\
\hline LEAD & $3(8)$ & $1(9)$ & $2(11)$ \\
\hline No statin & $2(5)$ & $2(11)$ & 0 \\
\hline Rosuvastatin & $29(78)$ & $15(79)$ & $14(78)$ \\
\hline Atorvastatin & $4(11)$ & $1(5)$ & $3(16)$ \\
\hline Pitavastatin & $2(5)$ & $1(5)$ & $1(5)$ \\
\hline Ezetimibe & $35(95)$ & $17(90)$ & $18(100)$ \\
\hline Fenofibrate & $3(8)$ & $2(11)$ & $1(6)$ \\
\hline Omega 3 fatty acids & $1(3)$ & 0 & $1(6)$ \\
\hline Colesevelam & $6(16)$ & $5(26)$ & $1(6)$ \\
\hline \multicolumn{4}{|l|}{ Intolerance to statins } \\
\hline Partial intolerance & $5(14)$ & $3(16)$ & $2(1)$ \\
\hline Total intolerance & $3(8)$ & $3(16)$ & 0 \\
\hline
\end{tabular}

Abbreviations: FH: familial hypercholesterolemia, LEAD: lower extremities arterial disease

\section{Lipid profile (Table 2 and Figure)}

PCSK9i administration yielded an additional $60 \%$ mean reduction in LDL-C and $42 \%$ mean reduction in TCHOL after 2 months on treatment $(p<0.05)$. This reduction rate remained sustainable after 1 and 2 years on PCSK9i therapy. The LDL-C and TCHOL lowering rate was similar among evolocumab and alirocumab treated group after 2 months, 1 and 2 years ( $p=N S$ for between groups comparison). HDL-C was increased by $3 \%$ and triglycerides were decreased by $10 \%$ after 2 -month PCKS9i treatment $(p=N S)$. The overall percentage of patients attaining LDL-C target according to ESC/EAS 2016 guidelines ${ }^{28}$ was $81 \%$ after 2-month PCSK9i

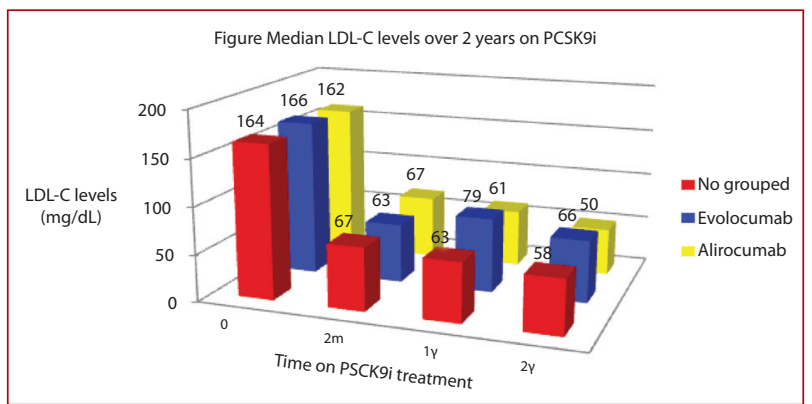

FIGURE 1. Median value of low-density lipoprotein cholesterol level (LDL-C) in all participants, according to treatment assignment and time on proprotein convertase subtilisin/kexin type 9 inhibitors (PCSK9i).

therapy. Excluding homozygous FH patients $(n=3)$, LDL-C was reduced by $63 \%$, TGs by $12 \%$, TCHOL by $42 \%$ and HDL-C was increased by $7 \%$ after 2 months on PCSK9i treatment. The 3 individuals with homozygous $\mathrm{FH}$ experienced a mean LDL-C reduction of $39 \%$ over a 2 -year follow-up.

\section{Safety (Table 3)}

The majority of patients (89\%) did not report any adverse event during follow-up. One patient complained about backache (evolocumab group), one patient reported diarrhea and abdominal pain (evolocumab group), one patient a non-troublesome reaction at the injection site (alirocumab group) and one patient reported a 'pruritic rash' in the upper body which resolved after few days and was not seen with next doses of PCK9i (evolocumab group). The reported adverse events were not different between 2 treated groups. No patient dropped out of treatment. No CVD event was reported during follow-up.

\section{DISCUSSION}

The present study is one of the few investigating the efficacy and safety of PCSK9i administration in a clinical real life setting ${ }^{20-26}$. Randomized controlled clinical trials frequently enlarge the magnitude of LDL-C lowering rate due to rigorous patient monitoring and intensive lifestyle modifications ${ }^{8-14}$. Our study indicates a mean LDL-C reduction rate comparable with that of FOURIER and ODYSSEY clinical trials (approximately 60\%) and similar with that achieved in real-life studies (50-63\%) ${ }^{20-26}$. It also confirms that PSCK9i-related LDL-C reduction was sustained after 1 and 2 years on treatment with both evolocumab and alirocumab having comparable efficacy.

Three individuals (8.1\%) with homozygous FH were responsive to PCSK9i on top of dual or triple hypolipidemic therapy and gained a mean percentage LDL-C level reduction of $39 \%$ over a 2 -year follow-up. This is line with the 
PCSK9 inhibitors: The breakthrough lipid-lowering treatment at real-life setting

TABLE 2. Baseline and post treatment lipid panel of study participants (follow-up: 2 years)

\begin{tabular}{|c|c|c|c|c|c|c|c|}
\hline & Baseline & 2 months & $\begin{array}{l}\text { Change from } \\
\text { baseline }\end{array}$ & 1 year & $\begin{array}{l}\text { Change from } \\
\text { baseline }\end{array}$ & 2 years & $\begin{array}{c}\text { Change from } \\
\text { baseline }\end{array}$ \\
\hline \multicolumn{8}{|l|}{$\mathrm{TCHOL}, \mathrm{mg} / \mathrm{dL}$} \\
\hline All patients & $240(200-277)$ & $140(120-177)$ & $-42 \% *$ & $133(113-169)$ & $-45 \% *$ & $116(106-138)$ & $-52 \% *$ \\
\hline Evolocumab & $241(199-312)$ & $142(124-193)$ & $-41 \% *$ & $152(127-195)$ & $-37 \% *$ & $144(138-149)$ & $-40 \% *$ \\
\hline Alirocumab & $239(202-268)$ & $138(115-169)$ & $-42 \%^{*}$ & $133(112-140)$ & $-44 \% *$ & $113(104-121)$ & $-53 \% *$ \\
\hline \multicolumn{8}{|l|}{ LDL-C, mg/dL } \\
\hline All patients & 164 (137-196) & $67(50-104)$ & $-59 \% *$ & $63(51-96)$ & $-62 \% *$ & $58(39-61)$ & $-64 \% *$ \\
\hline Evolocumab & $166(134-221)$ & $63(50-127)$ & $-62 \% *$ & $79(52-106)$ & $-52 \% *$ & $66(61-71)$ & $-60 \% *$ \\
\hline Alirocumab & 162 (139-189) & 67 (49-96) & $-59 \% *$ & $61(50-72)$ & $-62 \% *$ & $50(39-60)$ & $-69 \% *$ \\
\hline \multicolumn{8}{|l|}{$\mathrm{HDL}-\mathrm{C}, \mathrm{mg} / \mathrm{dL}$} \\
\hline All patients & $51(44-63)$ & $53(45-65)$ & $3 \%$ & $53(45-63)$ & $3 \%$ & $53(46-63)$ & $3 \%$ \\
\hline Evolocumab & $51(44-64)$ & $53(48-57)$ & $3 \%$ & $53(48-60)$ & $3 \%$ & $53(48-61)$ & $3 \%$ \\
\hline Alirocumab & $49(41-61)$ & $50(43-66)$ & $2 \%$ & $50(43-60)$ & $2 \%$ & $50(42-60)$ & $2 \%$ \\
\hline \multicolumn{8}{|l|}{$\mathrm{TGs}, \mathrm{mg} / \mathrm{dL}$} \\
\hline All patients & $116(75-173)$ & 104 (77-142) & $-10 \%$ & $104(93-138)$ & $-10 \%$ & $104(93-142)$ & $-10 \%$ \\
\hline Evolocumab & $126(89-173)$ & 113 (82-144) & $-10 \%$ & $113(100-147)$ & $-10 \%$ & 113 (98-147) & $-10 \%$ \\
\hline Alirocumab & $103(71-178)$ & $93(72-121)$ & $-10 \%$ & $93(84-130)$ & $-10 \%$ & $93(69-116)$ & $-10 \%$ \\
\hline
\end{tabular}

Values are expressed as median (interquartile range: IQR), ${ }^{*} \mathrm{p}<0.05$ for comparison values between baseline and during time. To convert from $\mathrm{mg} /$ $\mathrm{dL}$ to $\mathrm{mmol} / \mathrm{L}$ multiply by 0.02586 for cholesterol and by 0.01129 for triglycerides.

Abbreviations: TCHOL: total cholesterol, LDL-C: low-density lipoprotein cholesterol, HDL-C: high-density lipoprotein cholesterol, TGs: triglycerides

mean reduction rate of LDL-C reported by one published real-life study $(38 \%)^{26}$. In another trial in patients with homozygous FH, LDL-C was reduced by $20-65 \%$ after 12 weeks on PCSK9i. The magnitude of reduction was dependent on the underlying genetic defect with the greatest reduction noted in patients with PCSK9 gain of function mutations ${ }^{14}$

Of note, $90 \%$ of our patients were treated with highintensity statins. Two previously published real-life cohorts reported treatment rates with high-intensity statin regiments in $49 \%$ and $66 \%$ of participants, respectively ${ }^{23,26}$. This discrepancy could be attributed to different PSCK9i approval criteria applicable in each country. In Greece, LDL-C levels above treatment target despite high-intensity statin plus ezetimibe administration or maximally tolerated LLT comprises a precondition for PCSK9i reimbursement ${ }^{19}$. Of interest, in our study the percentage of LDL-C goal attainment was $81 \%$. This proportion is higher than other cohorts reporting LDL-C target achievement by $55-76 \% 20,22,24,26,29$

\section{Safety}

Our data verify the favorable safety profile of both evolocumab and alirocumab in daily clinical practice in line with randomized clinical trials. Minor adverse events were manifested by $6 \%$ of patients, a lower incidence than that reported in randomized clinical trials; there were no differences between evolocumab and alirocumab treatment groups. These side effects did not lead to treatment discontinuation and resolved spontaneously. Notably, in our study no treatment discontinuation was observed in contrast with other cohorts reporting a discontinuation range of $2.5-15.0 \%$, mainly due to non-adherence $20,22,24,26$. Interestingly, $8.1 \%$ of patients being intolerant to statins due to muscle symptoms did not report any muscle event with PCSK9i administration. In GAUSS-3 there was a higher percentage of muscle symptoms in ezetimibe compared with evolocumab group ${ }^{27}$.

\section{Limitations}

This study comprises real-life data from a relatively small number of patients attending a university outpatient lipid clinic. In this view, our findings may not be generalizable to other populations particularly to hospitals those without lipid clinics or to the private practice.

In conclusion, PCSK9i administration in a real-life clinical setting was associated with potent LDL-C reductions and a favorable safety profile during a 2-year follow-up 
TABLE 3. Baseline and post treatment laboratory reports of study participants (follow-up: 2 years)

\begin{tabular}{|c|c|c|c|c|c|}
\hline Laboratoryreports & Baseline & 2 months & Change from baseline & 1 year & Change from baseline \\
\hline \multicolumn{6}{|l|}{ AST, IU/L } \\
\hline All patients & $25 \pm 7$ & $29 \pm 18$ & $16 \%$ & $26 \pm 7$ & $4 \%$ \\
\hline Evolocumab & $24 \pm 7$ & $33 \pm 24$ & $38 \%$ & $25 \pm 8$ & $4 \%$ \\
\hline Alirocumab & $26 \pm 7$ & $24 \pm 8$ & $-8 \%$ & $27 \pm 6$ & $4 \%$ \\
\hline \multicolumn{6}{|l|}{ ALT, IU/L } \\
\hline All patients & $29 \pm 11$ & $33 \pm 25$ & $14 \%$ & $31 \pm 12$ & $7 \%$ \\
\hline Evolocumab & $30 \pm 12$ & $37 \pm 33$ & $23 \%$ & $34 \pm 15$ & $13 \%$ \\
\hline Alirocumab & $28 \pm 10$ & $28 \pm 12$ & $0 \%$ & $29 \pm 11$ & $4 \%$ \\
\hline \multicolumn{6}{|l|}{ CK, IU/L } \\
\hline All patients & $129(85-151)$ & $123(88-164)$ & $-5 \%$ & $180(123-331)$ & $40 \%$ \\
\hline Evolocumab & $137(112-145)$ & $129(93-191)$ & $-6 \%$ & $159(134-406)$ & $16 \%$ \\
\hline Alirocumab & $98(60-155)$ & $100(63-155)$ & $2 . \%$ & $180(122-322)$ & $82 \%$ \\
\hline \multicolumn{6}{|l|}{ Glucose, mg/dL } \\
\hline All patients & $98(95-106)$ & $100(95-111)$ & $2 \%$ & $97(93-117)$ & $-1 \%$ \\
\hline Evolocumab & 97 (94-101) & $99(95-106)$ & $2 \%$ & $97(90-101)$ & $0 \%$ \\
\hline Alirocumab & $100(96-111)$ & $109(90-124)$ & $9 \%$ & $106(93-118)$ & $6 \%$ \\
\hline \multicolumn{6}{|l|}{ Creatinine, mg/dL } \\
\hline All patients & $0.94 \pm 0.23$ & $0.97 \pm 0.23$ & $3 \%$ & $0.94 \pm 0.30$ & $0 \%$ \\
\hline Evolocumab & $0.87 \pm 0.12$ & $0.93 \pm 0.12$ & $7 \%$ & $0.85 \pm 0.12$ & $-2 \%$ \\
\hline Alirocumab & $1.02 \pm 0.29$ & $1.02 \pm 0.30$ & $0 \%$ & $0.98 \pm 0.35$ & $-4 \%$ \\
\hline \multicolumn{6}{|c|}{ eGFR, $\mathrm{mL} / \mathrm{min} / 1.73 \mathrm{~m}^{2}$} \\
\hline All patients & $83.3 \pm 18.93$ & $81.24 \pm 16.19$ & $-2 \%$ & $84.21 \pm 22.87$ & $1 \%$ \\
\hline Evolocumab & $88.31 \pm 14.93$ & $84.23 \pm 12.37$ & $-5 \%$ & $88.75 \pm 13.40$ & $0 \%$ \\
\hline Alirocumab & $78.31 \pm 21.56$ & $78 \pm 19.53$ & $-0 \%$ & $82.40 \pm 26.13$ & $5 \%$ \\
\hline
\end{tabular}

Values are expressed as median (interquartile range: IQR) and as means \pm SD.

Abbreviations: AST: aspartate transaminase, ALT: alanine transaminase, CK: creatine kinase, eGFR: estimated glomerular filtration rate

comparable to what is reported in randomized clinical trials.

\section{Authorship}

Dr. G. Anastasiou contributed to the conception and design, acquisition, analysis and interpretation of data and been involved in drafting the manuscript. Dr. E. Christopoulou and Dr. T. Dimitriou contributed to the analysis and interpretation of data. Dr. G. Liamis, Dr. H. Milionis and Prof. M. Elisaf have been involved in critically revising the manuscript. Dr. E. Liberopoulos has given the final approval of the version to be published and agreed to be accountable for all aspects of the work in ensuring that questions related to the accuracy or integrity of any part of the work are appropriately investigated and resolved.

\section{Funding}

The authors have received no payment in preparation of this manuscript.

\section{Conflict of interest}

AG, EC, and TD have nothing to declare; EL has participated in educational, research and advisory activities sponsored by Astra-Zeneca, MSD, Lilly, Bayer, Amgen, Sanofi, Boehringer-Ingelheim, Novartis, Novo Nordisk and Servier; HM reports receiving honoraria, consulting fees and non-financial support from healthcare companies including Amgen, Bayer, MSD, Mylan, Pfizer, Sanofi, and Servier; GL reports personal fees from Angelini, Bayer, Menarini and Sanofi; Professor M. Elisaf reports honoraria 
from MSD, Novartis, Chiesi, Bayer, Astra-Zeneca, Pfizer, Abbott, Mylan, Sanofi, Amgen, Boheringer-Ingelheim,
Lilly, GSK, Angelini, Winmedica and grants and personal fees from MSD and Astra-Zeneca.

\title{
ПЕРІАНЧН
}

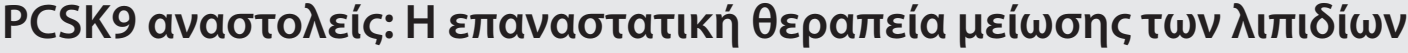

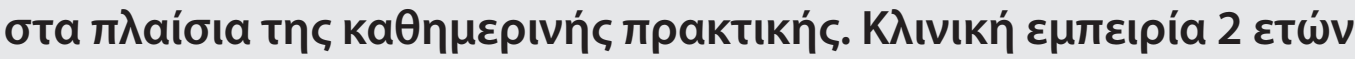

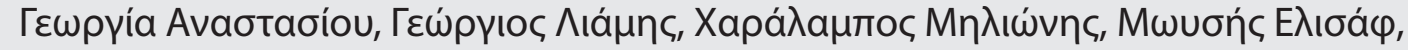

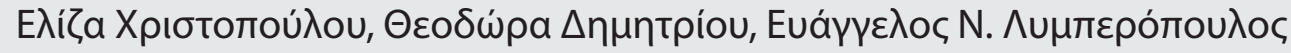

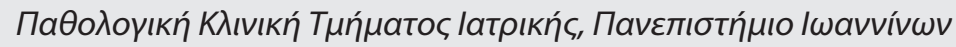

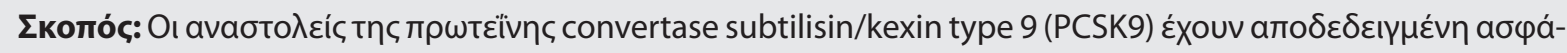

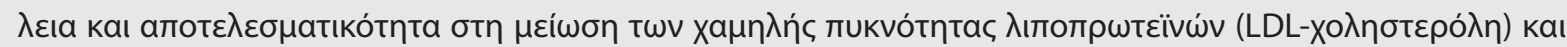

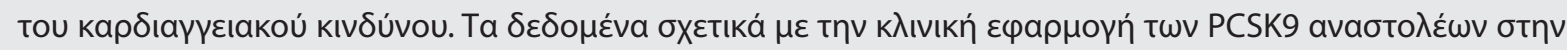

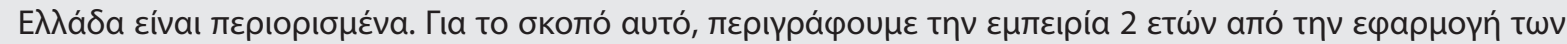

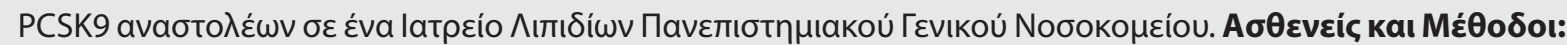

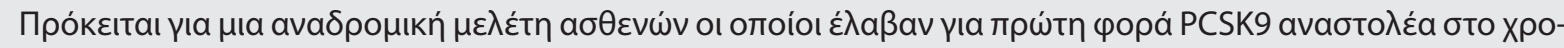

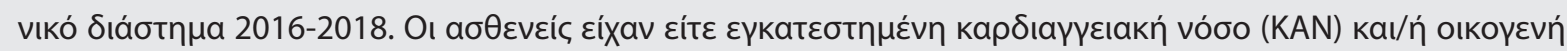

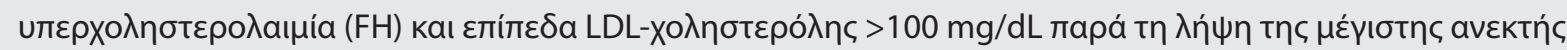

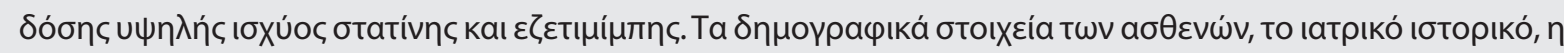

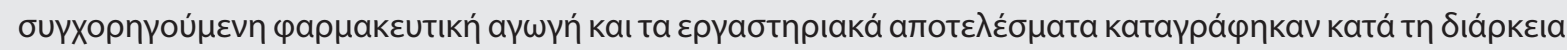

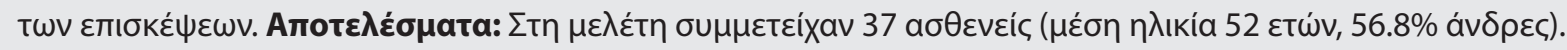

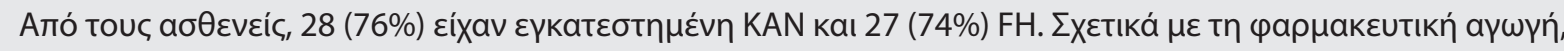

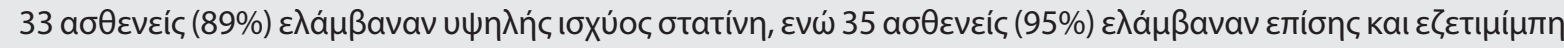

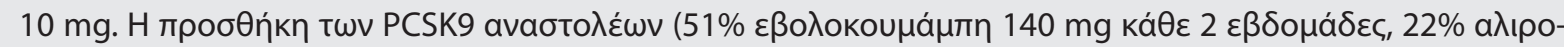

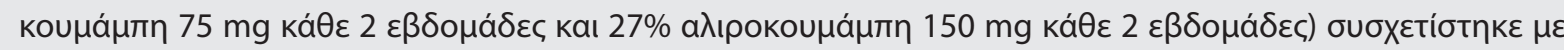

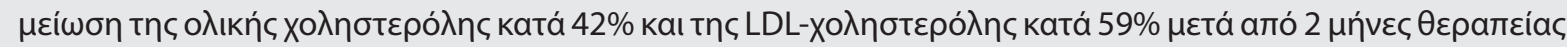

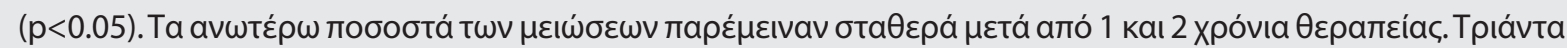

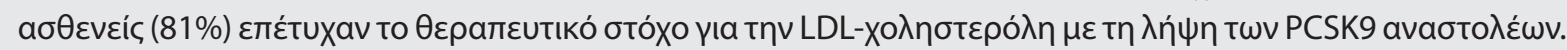

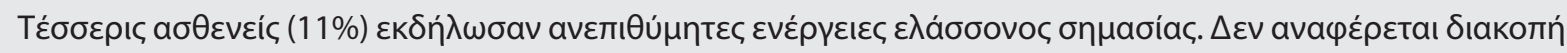

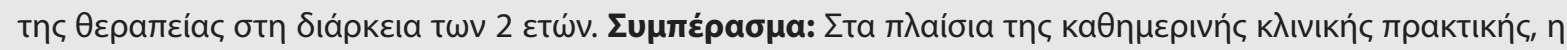

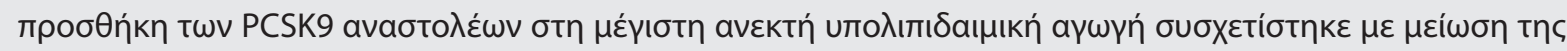

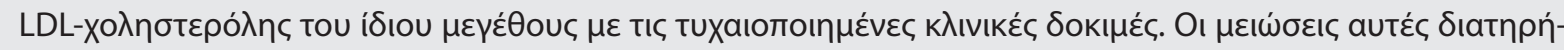

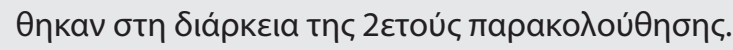

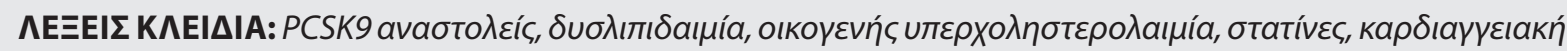

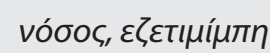

\section{REFERENCES}

1. Grundy SM, Stone NJ, Bailey AL, Beam C, Birtcher KK, Blumenthal RS, et al. 2018 AHA/ACC/AACVPR/AAPA/ ABC/ACPM/ADA/AGS/APhA/ASPC/NLA/PCNA guideline on the management of blood cholesterol: a report of the American College ofCardiology/American Heart Association Task Force on Clinical Practice Guidelines. J Am Coll Cardiol. 2019 Jun;73(24):3168-209.

2. Mach F, Baigent C, Catapano AL, Koskinas KC, Casula M,
Badimon L, et al. 2019 ESC/EAS Guidelines for the management of dyslipidaemias: lipid modification to reduce cardiovascular risk: The Task Force for the management of dyslipidaemias of the European Society of Cardiology (ESC) and European Atherosclerosis Society (EAS). Eur Heart J. 2020 Jan;41(1):111-88.

3. Kotseva K, De Backer G, De Bacquer D, Rydén L, Hoes A, Grobbee D, et al. Lifestyle and impact on cardiovascular risk factor control in coronary patients across 27 coun- 
tries: Results from the European Society of Cardiology ESC-EORP EUROASPIRE V registry. Eur J Prev Cardiol. 2019 May;26(8):824-35.

4. Liberopoulos E, Rallidis L, Spanoudi F, Elena Xixi, Anselm Gitt, Martin Horack, et al. Attainment of cholesterol target values in Greece: Results from the Dyslipidemia International Study II. Arch Med Sci. 2019 Jul;15(4):821-31.

5. Barkas F, Liberopoulos EN, Kostapanos MS, Liamis G, Tziallas D, Elisaf M. Lipid target achievementamong patientswithvery high and high cardiovascular risk ina lipid clinic. Angiology. 2015 Apr;66(4):346-53.

6. Sabatine MS, Giugliano RP, Keech AC, Honarpour N, Wiviott SD, Murphy SA, et al. Evolocumab and Clinical Outcomes in Patients with Cardiovascular Disease. N Engl J Med. 2017 May;376(18):1713-22.

7. Schwartz GG, Steg PG, Szarek M, Bhatt DL, Bittner VA, Diaz R, et al. Alirocumab and Cardiovascular Outcomes after Acute Coronary Syndrome. N Engl J Med. 2018 Nov;379(22):2097-107.

8. Koren MJ, Sabatine MS, Giugliano RP, Langslet G, Wiviott SD, Ruzza A, et al. Long-Term Efficacy and Safety of Evolocumab in Patients with Hypercholesterolemia. J Am Coll Cardiol. 2019 Oct;74(17):2132-46.

9. Wasserman SM, Sabatine MS, Koren MJ, Giugliano RP, Legg JC, Emery MG, et al. Comparison of LDL-C Reduction Using Different Evolocumab Doses and Intervals: Biological Insights and Treatment Implications. J Cardiovasc Pharmacol Ther. 2018 Sep;23(5):423-32.

10. Defesche JC, Stefanutti C, Langslet G, Hopkins PN, Seiz W, Baccara-Dinet MT, et al. Efficacy of alirocumab in 1191 patients with a wide spectrum of mutations in genes causative for familial hypercholesterolemia. J Clin Lipidol. 2017 Nov - Dec;11(6):1338-46.e7.

11. Stroes E, Guyton JR, Lepor N, Civeira F, Gaudet D, Watts GF, et al. Efficacy and Safety of Alirocumab 150 mg Every 4 Weeks in Patients with Hypercholesterolemia Not on Statin Therapy: The ODYSSEY CHOICE II Study. J Am Heart Assoc. 2016 Sep;5(9):e003421.

12. Toth PP, Sattar N, Blom DJ, Martin SS, Jones SR, Monsalvo $\mathrm{ML}$, et al. Effect of evolocumab on lipoprotein particles. Am J Cardiol. 2018 Feb;121(3):308-14.

13. Farnier M, Hovingh GK, Langslet G, Dufour R, BaccaraDinet MT, Din-Bell C, et al. Long-term safety and efficacy of alirocumab in patients with heterozygous familial hypercholesterolemia: An open-label extension of the ODYSSEY program. Atherosclerosis. 2018 Nov;278:307-14.

14. Raal FJ, Hovingh GK, Blom D, Santos RD, Harada-Shiba M, Bruckert E, et al. Long-term treatment with evolocumab added to conventional drug therapy, with or without apheresis,in patients with homozygous familial hypercholesterolaemia: An interim subset analysis of the openlabel TAUSSIG study. Lancet Diabetes Endocrinol. 2017 Apr;5(4):280-90.

15. Nicholls SJ, Puri R, Anderson T, Ballantyne CM, Cho L, Kastelein JP, et al. Effect of evolocumab on progression of coronary disease in statin-treated patients, The GLAGOV Randomized Clinical Trial. JAMA. 2016 Dec; 316(22):2373-84.

16. Koren MJ, Sabatine MS, Giugliano RP, Langslet G, Wiviott $\mathrm{SD}$, Kassahun $\mathrm{H}$, et al. Long-term low-density lipoprotein cholesterol-lowering efficacy, persistence, and safety of evolocumab in treatment of hypercholesterolemia. Results up to 4 Years from the open-label OSLER-1 extension study.
JAMA Cardiol. 2017 Jun;2(6):598-607.

17. Robinson JG, Farnier M, Krempf M, Bergeron J, Luc G, Averna M, et al.; for the ODYSSEY LONG TERM Investigators. Efficacy and safety of alirocumab in reducing lipids and cardiovascular events. N Engl J Med. 2015 Apr;372(16):1489-99.

18. Hovingh GK, Raal FJ, Dent R, Stefanutti C, Descamps O, Masana L, et al. Long-term safety, tolerability, and efficacy of evolocumab in patients with heterozygous familial hypercholesterolemia. J Clin Lipidol. 2017 Nov Dec;11(6):1448-57.

19. Achimastos A, Alexandrides T, Alexopoulos D, Athyros V, Bargiota A, Bilianou E, et al. Expert consensus on the rational clinical use of proprotein convertase subtilisin/ kexin type 9 (PCSK9) inhibitors. Hormones. 2016 Jan-Mar; 15(1):8-14.

20. Stoekenbroek RM, Hartgers ML, Rutte R, de Wijer DD, Stroes ESG, Hovingh GK, et al. PCSK9 inhibitors in clinical practice: Delivering on the promise? Atherosclerosis. 2018 Mar;270:205-210.

21. Sarsam S, Berry A, Degheim G, Singh R, Zughaib M. Realworld use of PCSK9 inhibitors: A single center experience. J Int Med Res. 2019 Jan;47(1):265-70.

22. Graesdal A, Dybvig A. A real-life PCSK9 experience: efficacy, compliance and side effects afteroneyear treatment in familial hypercholesterolemia patients. J Am Coll Cardiol. 2018 March; 71(11)Suppl DOI: 10.1016/S07351097(18)32295-2.

23. Navarro-Hoyas $C$, Moragrega Raquel $M$, Delegido-Gómez L, López-Muñoz B, Moreno-Pérez Ó, Picó-Alfonso A, et al. Efficacy and safety of proprotein convertase subtilisin/ kexintype nine inhibitors in real life experience. Endocrine In: 20th European Congress of Endocrinology. Vol 56. Bioscientifica. 2018.

24. Zafrir B, Jubran A. A Lipid-lowering therapy with PCSK9inhibitors in the real-world setting: Two-year experience of a regional lipid clinic. Cardiovasc Ther. 2018 Oct; 36(5):e12439.

25. Jensen JS, Weeke PE, Bang LE, Høfsten DE, Sejersten Ripa $M$, Schjerning AM, et al. Clinical characteristics and lipid lowering treatment of patients initiated on proprotein convertase subtilisin-kexin type 9 inhibitors: A nationwide cohort study. BMJ Open. 2019 Apr 1;9(4):e022702

26. Galema-Boers AMH, Lenzen MJ, Sijbrands EJ, Roeters van Lennep JE. Proprotein convertase subtilisin/kexin 9 inhibition in patients with familial hypercholesterolemia: Initial clinical experience. J Clin Lipidol. 2017 May - Jun;11(3):67481.

27. Nissen SE, Stroes E, Dent-Acosta RE, Rosenson RS, Lehman SJ, Sattar N, et al. Efficacy and tolerability of evolocumab vs ezetimibe in patients with muscle-related statin intolerance: The GAUSS-3 randomized clinical trial. JAMA. 2016 Apr;315(15):1580-90.

28. Catapano AL, Graham I, De Backer G, Wiklund O, Chapman MJ, Drexel H. 2016 ESC/EAS Guidelines for the Management of Dyslipidaemias. Eur Heart J. 2016 Oct 14; 37(39): 2999-3058.

29. Rallidis LS, Skoumas I, Liberopoulos EN, Vlachopoulos C, Kiouri E, Koutagiar I, et al. PCSK9 inhibitors in clinical practice: Novel directions and new experiences. Hellenic J Cardiol. 2019 Nov 26. pii: S1 109-9666(19)30276-3. doi: 10.1016/j.hjc.2019.10.003. [Epub ahead of print] 